\title{
Kronik böbrek yetmezliği tanılı hastalarda üst gastrointestinal sisteme ait endoskopik ve histolojik bulguların değerlendirilmesi
}

\author{
Endoscopic and histological assessment of the upper gastrointestinal tract in patients with chronic \\ kidney disease
}

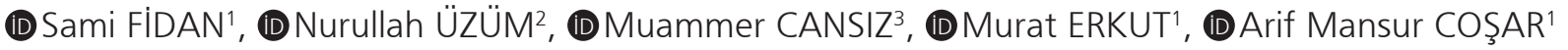

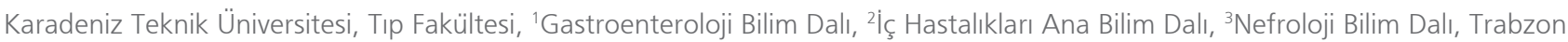

\begin{abstract}
Giriş ve Amaç: Kronik böbrek yetmezliği olan hastalarda üst gastrointestinal sistem bulguları oldukça sık görülmektedir. Bu çalışmada kronik böbrek yetmezliği olan hastalarda üst gastrointestinal sisteme ait endoskopik ve histolojik bulgularının değerlendirilmesi amaçlanmıştır. Gereç ve Yöntem: Hastanemizde Ocak 2013 ile Aralık 2018 tarihleri arasında kronik böbrek yetmezliği tanısı ile takip edilen ve herhangi bir nedenle endoskopi yapılan hastaların sonuçları retrospektif olarak değerlendirildi. Hastalar hemodiyalize alınanlar, sürekli ayaktan periton diyalizi yapılanlar ve diyalize girmeyenler olarak gruplandırıldı. Bulgular: Çalışmaya toplam 493 hasta dahil edildi (yaş ortalaması 57.02 \pm 16.3 , $\% 64.1$ erkek). Hastaların 270'i hemodiyaliz, 34'ü sürekli ayaktan periton diyalizi ve 189 tanesi ise diyalize girmeyen gruptaydı. Hastaların $\% 83^{\prime}$ ünde anormal endoskopik bulgu saptandı. Gruplar arasında anormal endoskopik bulgu saptanma oranı benzerdi (hemodiyaliz; \%83.7, periton diyalizi; \%73.5, diyalize girmeyenler; \%83.6, p:0.317). Her üç hasta grubunda en sık görülen endoskopik bulgu gastrit idi (\%67.7). Histolojik değerlendirme yapılan 320 hastanın \%24'ünde Helicobacter pylori pozitifliği, \%26.6'sında intestinal metaplazi ve \%0.9'unda mide kanseri tespit edildi. Sonuç: Kronik böbrek yetmezliği tanılı hastaların büyük çoğunluğunda üst gastrointestinal sisteme ait patolojiler görülmektedir. Bu hastalarda premalign gastrik lezyonlar sık görüldüğü için özellikle böbrek nakli planlanan hastalarda endoskopik değerlendirme kabul edilebilir bir prosedürdür.
\end{abstract}

Anahtar kelimeler: Kronik böbrek hastalığı, Helicobacter pylori, hemodiyaliz, endoskopi, endoskopik bulgular
Background and Aims: Symptoms occurring in the upper gastrointestinal tract are common among patients with chronic kidney disease. This study aimed to assess the endoscopic and histological findings in the upper gastrointestinal tract of patients with chronic kidney disease. Materials and Methods: We retrospectively evaluated the data of patients with chronic kidney disease who underwent follow up examinations in our hospital between January 2013 and December 2018 and who underwent endoscopy, regardless of the etiology. Patients were categorized according into the following three groups: hemodialysis, continuous ambulatory peritoneal dialysis, and nondialysis. Results: We studied the data of 493 patients (mean age, $57.02 \pm 16.3$ years, $64.1 \%$ men), of which 270 were categorized in the hemodialysis, 34 in continuous ambulatory peritoneal dialysis, and 189 in the nondialysis groups. Abnormal endoscopic findings were detected in $83 \%$ of the patients, and the rates of these findings were similar for the three groups, i.e., the hemodialysis groups showed a rate of $83.7 \%$, continuous ambulatory peritoneal dialysis showed $73.5 \%$, and nondialysis group showed $83.6 \%(P=0.317)$. The most common endoscopic finding in all patients was gastritis (67.7\%). Total 320 patients underwent histological evaluation. Helicobacter pylori infection, intestinal metaplasia, and gastric cancer rates for the hemodialysis, continuous ambulatory peritoneal dialysis, and nondialysis groups were $24 \%, 26.6 \%$, and $0.9 \%$, respectively. Conclusion: Most patients with chronic kidney disease have disorders of the upper gastrointestinal tract. Since premalignant gastric lesions are common in these patients, endoscopic evaluation is an acceptable procedure, particularly in those awaiting kidney transplantation.

Key words: Chronic kidney disease, Helicobacter pylori, hemodialysis, endoscopy, endoscopic findings

kalemi, asidoz gibi durumların sıklıkla görülmesinin gastroduodenal lezyonların ve semptomların gelişmesinde rol oynayabileceği ileri sürülmüştür $(1,2)$.

KBH hastalarında üst Gis bulguları oldukça sık görüldüğü için bu hastalarda endoskopik bulguların değerlendirildiği birçok çalışma yapılmıştır. Ancak bu çalışmalar arasında bazı tutarsızlıklar bulunmaktadır. Bazı çalışmalarda üst GiS'te KBH hastalarında kontrol grubuna göre daha fazla oranda erozyon, ülser, özofajit, gastrit, Helicobacter

Fidan S, Üzüm N Cansiz M, et al. Endoscopic and histological assessment of the upper gastrointestinal tract in patients with chronic kidney disease. The Turkish Journal of Academic Gastroenterology 2020;19:57-62. DOI: 10.17941/ agd.798097

Geliş Tarihi: 13.05.2020 • Kabul Tarihi: 20.08.2020
Karadeniz Teknik Üniversitesi, Tıp Fakültesi, Gastroenteroloji Bilim Dalı, Trabzon • Tel: +90462 3775550 • Faks: +90 4623252270 E-mail: fidansami@yahoo.com 
pylori (H. pylori) pozitifliği bildirilmiştir (3-5). Bazı çalışmalarda ise bu bulguların normal popülasyona göre $\mathrm{KBH}$ hastalarında daha az görüldüğü veya farklı olmadığı ileri sürülmüştür (6-8). Çalışmamızda kronik böbrek yetmezliği tanısı olan hastalarda üst Gis endoskopik bulgularının değerlendirilmesi amaçlanmıştır.

\section{GEREÇ ve YÖNTEM}

Çalışmamızda Ocak 2013 ile Aralık 2018 tarihleri arasında Karadeniz Teknik Üniversitesi Tıp Fakültesi Nefroloji Polikliniği'ne başvuran ve herhangi bir nedenle gastroskopi yapılan $\mathrm{KBH}$ tanılı hastaların endoskopi verileri retrospektif olarak değerlendirildi. Hastalar hemodiyaliz (HD) yapılanlar, sürekli ayaktan periton diyalizi (SAPD) yapılanlar ve diyalize girmeyenler olarak gruplandırılı. HD grubundaki hastalara haftada 3 kez 4.5 saat bikarbonatlı diyaliz yapilırken, SAPD grubundakilere standart dekstrozlu solüsyonlar ile günde 4-5 defa 2 litrelik değişim yapılmakta idi. Akut böbrek yetmezliği olan hastalar, 18 yaş altındakiler ve endoskopi yapılmayan hastalar çalışmaya dahil edilmedi. Hasta dosyalarından hastaların demografik ve klinik özellikleri, endoskopi yapılma endikasyonları, üst GIS endoskopi bulguları ve laboratuvar verileri analiz edildi. Hastaların endoskopi yapıldığı zamandaki glomerüler filtrasyon hızı (GFR) (mL/dk/1.73m2) hesaplanmasında Chronic Kidney Disease Epidemiology Collaboration (CKD-EPI) formülü kullanıldı. Çalışma süresi boyunca kan üre azotu, kreatinin, albümin gibi biyokimyasal parametreler bir Beckman Coulter AU 5800 otoanalizörü (Shizu- oka, Japonya) kullanılarak test edildi. Serolojik belirteçler ise Roche Cobas E601 cihazında (Japonya) elektrokemilüminesans immünoanaliz kullanılarak ölçüldü. $H$. pylori varlığı hematoksilen eozin ve Giemsa boyaları kullanılarak histolojik olarak değerlendirildi. Histopatolojik olarak mide mukoza ve gland epitelinin intestinal epitele benzer morfolojik değişiklikler göstermesi intestinal metaplazi olarak tanımlandı. Çalışma, Helsinki Deklarasyonu ilkelerine uygun olarak gerçekleştirildi ve çalışma protokolü Karadeniz Teknik Üniversitesi Tıp Fakültesi Bilimsel Araştırmalar Etik Kurulu tarafından onaylandı (Etik Kurul Onay Numarası: 2018/173).

\section{İstatistiksel Analiz}

Elde edilen verilerin istatistik değerlendirilmesi SSPS 23.0 for Windows (Statistical Package for the Social Sciences 23) paket programı kullanılarak yapıldı. Üzerinde durulan özelliklerden sürekli değişkenler için tanımlayıcı istatistikler ortalama, standart sapma, minimum ve maksimum değer olarak ifade edilirken, kategorik değişkenler sayı ve yüzde olarak ifade edildi. Normal dağılıma uygunluğun değerlendirilmesinde Kolmogorov-Smirnov testi uygulandı. Sürekli değişkenlerin gruplarını karşılaştırmada bağımsız iki farklı grubun karşılaştııımasında Mann Whitney U testi kullanıldı. Bağımsız ikiden fazla grubun karşılaştııılmasında Kruskal Wallis testi uygulandı. Kategorik değişkenler arasındaki ilişkileri belirlemede ise ki-kare testi kullanıldı. Gruplar arasındaki farkın belirlenmesinde $p<0.05$ değeri istatistiksel olarak anlamlı kabul edildi.

Tablo 1. Üst gastrointestinal sistem endoskopisi yapılan kronik böbrek hastalarının demografik özellikleri ve laboratuvar verileri

\begin{tabular}{|c|c|c|c|c|c|}
\hline & $\begin{array}{c}\text { HD } \\
(n=270) \\
(\% 54.8)\end{array}$ & $\begin{array}{c}\text { SAPD } \\
(n=34) \\
(\% 6.9)\end{array}$ & $\begin{array}{c}\text { Diyalize } \\
\text { Girmeyenler } \\
(n=189) \\
(\% 38.3)\end{array}$ & $\begin{array}{l}\text { Toplam } \\
(n=493)\end{array}$ & $\mathbf{p}$ \\
\hline Yaş (yıl) & $54.2 \pm 14.5$ & $41.7 \pm 15.1$ & $63.8 \pm 15.9$ & $57.02 \pm 16.3$ & $<0.001$ \\
\hline Cinsiyet (K/E) & $103 / 167$ & $19 / 15$ & $55 / 134$ & $177 / 316$ & 0.006 \\
\hline Kreatinin $(\mathrm{mg} / \mathrm{dL})$ & $5.68 \pm 2.55$ & $8.9 \pm 3.32$ & $2.19 \pm 1.12$ & $4.56 \pm 2.99$ & $<0.001$ \\
\hline BUN (mg/dL) & $54.4 \pm 23$ & $59.4 \pm 21.2$ & $39.9 \pm 20.2$ & $49.2 \pm 23$ & $<0.001$ \\
\hline Ürik asit (mg/dL) & $5.9 \pm 2.1$ & $6.1 \pm 2$ & $7.2 \pm 1.8$ & $6.4 \pm 2.1$ & $<0.001$ \\
\hline Albümin (g/dL) & $3.7 \pm 0.7$ & $3.5 \pm 0.5$ & $3.6 \pm 0.7$ & $3.7 \pm 0.7$ & 0.246 \\
\hline Hemoglobin ( $\mathrm{g} / \mathrm{dL})$ & $10.9 \pm 2.2$ & $10.8 \pm 1.7$ & $11.4 \pm 2.3$ & $11.1 \pm 2.2$ & 0.165 \\
\hline $\mathrm{HbsAg}(+)$ & $17(\% 6.3)$ & - & $9(\% 4.8)$ & $26(\% 5.3)$ & \\
\hline Anti HCV (+) & $13(\% 4.8)$ & $1(\% 2.9)$ & $4(\% 2.1)$ & $18(\% 3.7)$ & \\
\hline Anti HIV (+) & $1(\% 0.4)$ & - & - & $1(\% 0.2)$ & \\
\hline
\end{tabular}

HD: Hemodiyaliz; SAPD: Sürekli ayaktan periton diyalizi; BUN: Kan üre azotu; HbsAg: Hepatit B yüzey antijeni; HCV: Hepatit C virüsü: HIV; Insan immün yetmezlik virüsü. 


\section{BULGULAR}

$\mathrm{KBH}$ tanısı olup üst Gís endoskopi işlemi yapılmış 316'sı (\%64.1) erkek, 177'si (\%35.9) kadın toplam 493 hasta çalışmaya alındı. Hastaların 270 tanesi HD, 34 tanesi SAPD, 189 tanesi ise diyalize girmeyen gruptaydı. Hastaların demografik özellikleri ve laboratuvar verileri Tablo 1 'de gösterilmiştir. HD ve SAPD yapılan hastalarda en sık üst GiS endoskopi endikasyonu böbrek nakli hazırlığı iken diyalize girmeyenlerde kanser taraması idi. Hastaların üst GiS endoskopi endikasyonları Tablo 2'de gösterilmiştir. Her üç hasta grubunda en sık görülen endoskopik bulgu gastrit idi (\%67.7) ve bunu HD'ye giren grupta duodenit, SAPD'ye giren ve diyalize girmeyen gruplarda özofajit takip etti. HD grubunda duodenit, SAPD grubunda ise duodenal ülser diğer patolojilere göre anlamlı olarak daha yüksek bulundu. Diğer endoskopik bulgular açısından gruplar arasında fark saptanmadı (Tablo 3). Hastaların 320 tanesine (\%65) endoskopik biyopsi yapıldı. Biyopsi yapılan hastaların \%24'ünde $H$. pylori pozitifliği, \%26.6'sında ise intestinal metaplazi tespit edildi (Tablo 4).

\section{Tablo 2. Kronik böbrek hastalarında üst gastrointestinal sistem endoskopisi endikasyonları}

\begin{tabular}{|lcccc|}
\hline Endikasyon & $\begin{array}{c}\text { HD } \\
(\mathbf{n = 2 7 0 )} \\
(\mathbf{\% 5 . 8 )}\end{array}$ & $\begin{array}{c}\text { SAPD } \\
(\mathbf{n = 3 4 )} \\
(\% \mathbf{6 . 9})\end{array}$ & $\begin{array}{c}\text { Diyalize } \\
\text { Girmeyenler } \\
(\mathbf{n = 1 8 9 )} \\
\mathbf{( \% 3 8 . 3 )}\end{array}$ & $\begin{array}{c}\text { Toplam } \\
(\mathbf{n}=\mathbf{4 9 3})\end{array}$ \\
\hline Dispepsi & $28(\% 10.3)$ & $3(\% 8.8)$ & $40(\% 21.2)$ & $71(\% 14.4)$ \\
\hline Kusma & $4(\% 1.5)$ & - & $5(\% 2.6)$ & $9(\% 1.8)$ \\
\hline İshal & $1(\% 0.4)$ & - & $2(\% 1.1)$ & $3(\% 0.6)$ \\
\hline Gis Kanama & $36(\% 13.3)$ & $2(\% 5.9)$ & $23(\% 12.2)$ & $61(\% 12.4)$ \\
\hline Kanser taraması & $28(\% 10.4)$ & - & $49(\% 25.9)$ & $77(\% 15.6)$ \\
\hline Nakil hazırlığı & $151(\% 56)$ & $27(\% 79.4)$ & $26(\% 13.7)$ & $204(\% 41.4)$ \\
\hline
\end{tabular}

HD: Hemodiyaliz; SAPD: Sürekli ayaktan periton diyalizi; GiS: Gastrointestinal sistem.

\section{Tablo 3. Kronik böbrek hastalarında üst gastrointestinal sistem endoskopisi bulgularının karşılaştırılması}

\begin{tabular}{|c|c|c|c|c|c|}
\hline $\begin{array}{l}\text { Endoskopi } \\
\text { Bulguları }\end{array}$ & $\begin{array}{c}\text { HD } \\
(n=270)\end{array}$ & $\begin{array}{l}\text { SAPD } \\
(n=34)\end{array}$ & $\begin{array}{c}\text { Diyalize } \\
\text { Girmeyenler } \\
(n=189)\end{array}$ & $\begin{array}{l}\text { Toplam } \\
(n=493)\end{array}$ & $p$ \\
\hline Anormal bulgu & $226(\% 83.7)$ & $25(\% 73.5)$ & 158 (\%83.6) & $409(\% 83)$ & 0.317 \\
\hline Özofagit & $49(\% 18.1)$ & $10(\% 29.4)$ & $42(\% 22.2)$ & $101(\% 20.5)$ & 0.232 \\
\hline Gastrit & $193(\% 71.4)$ & $20(\% 58.8)$ & $121(\% 64)$ & $334(\% 67.7)$ & 0.125 \\
\hline Duodenit & $71(\% 26.3)$ & 7 (\%20.6) & $29(\% 15.3)$ & $107(\% 21.7)$ & 0.020 * \\
\hline Gastrik ülser & $8(\% 3)$ & $0(\% 0)$ & $5(\% 2.6)$ & $13(\% 2.6)$ & - \\
\hline Duodenal ülser & $16(\% 5.9)$ & $5(\% 14.7)$ & $6(\% 3.2)$ & $27(\% 5.5)$ & $0.022 * *$ \\
\hline Telenjiektazi & $2(\% 0.7)$ & $1(\% 2.9)$ & $3(\% 1.6)$ & $6(\% 1.2)$ & - \\
\hline Gastrik polip & $10(\% 3.7)$ & $1(\% 2.9)$ & 7 (\%3.7) & $18(\% 3.7)$ & 0.974 \\
\hline Hiatal herni & 9 (\%3.3) & $1(\% 2.9)$ & $12(\% 6.3)$ & $22(\% 4.5)$ & 0.277 \\
\hline
\end{tabular}

HD: Hemodiyaliz; SAPD: Sürekli ayaktan periton diyalizi.

*Diyalize girmeyen grup ile HD grubu arasındaki karşılaştırmada p=0.005 iken, diğer gruplar arası karşılaştırmada anlamlı fark saptanmadı.

**Diyalize girmeyen grup ile SAPD grubu arasındaki karşılaştırmada $p=0.014$ iken, diğer gruplar arası karşılaştırmada anlamlı fark saptanmadı. 


\begin{tabular}{|c|c|c|c|c|c|}
\hline Histopatoloji & $\begin{array}{c}\text { HD } \\
(n=183)\end{array}$ & $\begin{array}{l}\text { SAPD } \\
(n=19)\end{array}$ & $\begin{array}{c}\text { Diyalize } \\
\text { Girmeyenler } \\
(n=118)\end{array}$ & $\begin{array}{l}\text { Toplam } \\
(n=320)\end{array}$ & p \\
\hline İntestinal metaplazi & $44(\% 24)$ & $4(\% 21)$ & $37(\% 31,4)$ & $85(\% 26.6)$ & 0.320 \\
\hline Displazi & $0(\% 0)$ & $0(\% 0)$ & $2(\% 1.7)$ & $2(\% 0.6)$ & - \\
\hline Mide kanseri & $1(\% 0.4)$ & $0(\% 0)$ & $2(\% 1.7)$ & $3(\% 0.9)$ & - \\
\hline Helicobacter pylori $(+)^{*}$ & $47(\% 25.8)$ & $3(\% 15.8)$ & $27(\% 23.5)$ & $77(\% 24)$ & 0.601 \\
\hline
\end{tabular}

HD: Hemodiyaliz; SAPD: Sürekli ayaktan periton diyalizi.

*Helicobacter pylori sonucu patolojide belirtilmemiş olan 4 hasta dışlanarak yapılmıştır.

\section{TARTIŞMA}

KBH'lı hastalarda üst Gis endoskopi bulgularını değerlendirdiğimiz çalışmamızda hastaların \%83'ünde anormal endoskopik bulgu saptadık. Çalışmamıza benzer olarak Nardone G. ve arkadaşlarının $50 \mathrm{KBH}$ ve 93 normal böbrek fonksiyonuna sahip hastada yaptıkları çalışmada, üremik hastaların \%90'ında anormal endoskopik bulgu saptanmışken böbrek hastası olmayanlarda bu oran \%54 olarak bildirilmiştir (5). Benzer olarak yakın zamanda 293 böbrek nakli adayında yapılan bir çalışmada hastaların \%78.8'inde, 96 böbrek nakil adayının dahil edildiği başka bir çalışmada ise neredeyse hastaların tamamında anormal gastrik patolojik bulgu rapor edilmiştir $(9,10)$. Çalışmamızda en sık tespit ettiğimiz üst GiS endoskopik bulguları sırasıyla gastrit (\%67.7), duodenit (\%21.7) ve özofajit (\%20.5) olup bu bulgular literatür bulguları ile uyumluydu. Bu konu ile ilgili çalışmaların çoğunda patolojik endoskopik bulguların $\mathrm{KBH}^{\prime}$ da kontrol grubuna göre daha fazla oranda görüldüğü rapor edilmiştir. $\mathrm{KBH}$ hastalarında üst GiS endoskopi bulgularının değerlendirildiği çalışmalarda gastrit \%28-77, duodenit \%12-43.3 ve özofajit \%16-50 oranlarında bildirilmiştir (3-5,9-11). Ancak karşıt olarak Stolic RV. ve arkadaşlarının $124 \mathrm{KBH}$ hastası ve 120 kişilik kontrol grubu ile yapmış olduğu çalışmada, gastroduodenal lezyonlar kontrol grubunda anlamlı olarak daha yüksek bulunmuş ve böbrek yetmezliği seviyesi ile anlamlı negatif korelasyon olduğu belirtilmiştir (6). Aynı çalışmada $H$. pylori enfeksiyonu açısından da böbrek yetmezliği arasında negatif korelasyon olduğu saptanmış ve gastroduodenal lezyonların $\mathrm{KBH}$ hastalarında daha az görülmesinin, $H$. pylori enfeksiyon oranının daha az olması ile ilişkili olduğu ileri sürülmüştür (6). Kang ve arkadaşlarının üremik hastalarla sağlıklı gönüllüleri karşılaştırdığı başka bir çalışmada ise histolojik olarak gastritin, üremik hastalarda daha az oranda görüldüğü bildirilmiştir. Bu çaışmada üremik hastalarının sadece $\% 2$ 'sinde peptik ülse- rin görüldüğü ve bunun da genel popülasyonda gözlenen oranlara benzer olduğu bildirilmiştir (7).

$\mathrm{KBH}$ hastalarında gastroduodenal erozyon ve/veya ülserlerin patogenezi net olarak bilinmemektedir. $\mathrm{KBH}$ hastalarında genellikle artmış üre seviyeleri, azalmış gastrointestinal motilite, diyaliz etkisi ve çok sayıda ilaç kullanımı gibi nedenlerle üst GiS bulgularına sık rastlanmaktadır $(1,2)$. Gastrin böbrek yoluyla temizlendiği için $\mathrm{KBH}^{\prime}$ da açlık serum gastrin seviyelerinin genellikle yüksek olduğu, bu nedenle $\mathrm{KBH}$ olan hastalarda hipergastrinemi ve bunu takiben asit hipersekresyonu sonucu üst gastrointestinal lezyonların geliştiği düşünülmektedir (12). HD hastalarında gastrit oranının yüksek olmasının HD seansları esnasında mide kanlanmasındaki değişimlere bağlı olabileceği ileri sürülmüştür (4). Ayrıca böbrek yetmezliklerinde kolesistokinin, nörotensin, glukagon gibi açlık ve tokluk regülasyonu ve gastrointestinal motilite düzenlenmesinde rol oynayan hormonların serum seviyelerinin artmış olmasının ve hiperkalsemi, hipokalemi, asidoz gibi durumların sıklıkla görülmesinin de gastroduodenal lezyonların gelişmesinde rol oynayabileceği ileri sürülmüştür (13). $\mathrm{KBH}$ hastalarında gastrik sıvıdaki yüksek üre seviyesine sekonder metabolik değişikliklere bağlı olarak lezyonların gelişebileceği görüşü de vardır (3). Ayrıca safra asitlerinin reflüsü ve/veya pankreatik enzimlerin de gastroduodenal lezyonların gelişmesinde potansiyel sebepler arasında sayılabileceği vurgulanmıştır (4).

Gastrik intestinal metaplazi (IM) prekanseröz bir durum olup, genel popülasyonda iM tanısı olan bireylerde 3, 5 ve 10 yıllık kümülatif mide kanseri gelişme oranları sırası ile \%0.4 (\%95 Cl, \%0.1-\%0.8); \%1.1 (\%95 Cl, \%1.0\%1.2); ve \%1.6 (\%95 Cl, \%1.5-\%1.7) olarak bildirilmiştir (14). Amerika Birleşik Devletleri'nde endikasyona bakılmaksızın gastrik biyopsisi olan 897371 hastanın değer- 
lendirildiği bir metaanalizde intestinal metaplazi (IM) prevalansı \%4.8 (\%95 Cl, \%4.8-\%4.9) olarak rapor edilmiştir (15). Uluslararası veri tabanlarından elde edilen IM prevalansı ise \%3.4 ile \%29.6 arasında değişmektedir (15). Genel popülasyona göre KBH hastalarında intestinal metaplazinin daha fazla oranda görüldüğü düşünülmektedir $(3,16)$. Çalışmamızda ise histopatolojik inceleme yapılan $\mathrm{KBH}$ hastalarının \%26.6'sında IM, \%0.9'unda ise invaziv kanser saptadık. Misra V. ve arkadaşlarının 50 kişilik $\mathrm{KBH}$ grubu ve 50 kişilik kontrol grubu ile yapmış oldukları çalışmada da benzer şekilde KBH hastalarında \%29.4 oranında gastrik metaplazi saptanmışır (3). Huang C. ve arkadaşlarının 406 kişilik HD hastası grubunda yapmış olduğu başka bir çalışmada ise hastaların \%35'inde gastrik metaplazi saptanmıştır (16). Erkek hastalarda ve yaşlı hastalarda daha yüksek saptanmış olması nedeni ile gastrik metaplazi riskinin yaş ve erkek cinsiyetle ilişkili olabileceği belirtilmektedir. Ilgili çalışmada gastrik asit seviyesi ölçülmemiş olmakla birlikte yüksek gastrik asit seviyesi ile de ilişkili olabileceği ileri sürülmüştür (16). Ancak Nikman ve arkadaşları tarafından 293 böbrek nakli adayında yapılan bir çalışmada hastaların sadece \%6.1'inde premalign gastrik lezyon bildirilmiştir (9). Benzer olarak Homse Netto ve arkadaşlarının böbrek nakli adaylarında gastrointestinal değişiklikleri değerlendirmek için 96 hasta üzerinde yaptıkları bir çalışmada ise hastaların \%8.3'ünde IM bildirilmiştir (10).

$H$. pylori, insanlarda en yaygın görülen kronik bakteriyel enfeksiyondur ve gastrit, peptik ülser ve mide kanseri gibi çeşitli gastrointestinal hastalıklarla ilişkilidir. Böbrek fonksiyon bozukluğu olan hastalarda gastrointestinal hastalıkların ana nedenlerinden biri olarak kabul edilmektedir (17). Bununla birlikte, epidemiyolojik çalışmalarda H. pylori enfeksiyonu ve $\mathrm{KBH}$ arasındaki ilişki çelişkilidir (18). Bazı çalışmalarda kontrol grubuna göre KBH hastalarında $H$. pylori prevalansı daha sık görülürken $(4,5)$ diğerlerinde tam tersi sonuçlar bulunmuştur $(6,19)$. Bu tutarsızlığın nedeni, çalışmalar arasında $H$. pylori tespiti için kullanılan yöntem, KBH evresi ve diyaliz yöntemindeki farklııklardan kaynaklanabilir. Çalışmamızda histopatolojik inceleme için biyopsi alınan 320 hastada H. pylori pozitifliğini \%24 olarak saptadık. Diyalize giren ya da girmeyen hastalar arasında H. pylori pozitifliği bakımından anlamlı fark yoktu (p: 0.601). Çalışmamızda sağlıklı kontrol grubu olmamasına rağmen yakın zamanda aynı bölgede KBH olmayan hastalarda yaptığımız bir çalışmamızda H. pylori pozitiflik oranını \%40.4 olarak tespit etmiştik (20). Yakın zamanda diyaliz hastaları ve diyalize girmeyen kronik böbrek hastalarını içeren 47 çalışmanın değerlendirildiği bir metaanalizde $H$. pylori enfeksiyonu prevalansı KBH hastalarında kontrol grubuna göre anlamI derecede düşük bulunmuştur (KBH hastalarında $\% 48.2$ (1968/4.084), kontrol grubunda \%59.3 (4097/6908) idi (OR, 0.64; \%95 Cl, 0.52-0.79) (18). KBH hastalarında $H$. pylori prevalansının düşük olmasının patogenezi tam olarak bilinmemesine rağmen bu konuda çeşitli hipotezler ileri sürülmüştür. İlk olarak, KBH hastalarında antiasitlerin veya antibiyotiklerin sık kullanımı bu hastalarda $H$. pylori prevalansı azalmasıyla ilişkili olabilir (21). Öte yandan bu hastalarda yüksek düzeyde kan üre düzeyleri, artan enflamatuar sitokinlere bağlı olarak gelişen gastrik mukozal atrofi ve hipokloridi $H$. pylori kolonizasyonunu azaltabilir $(17,18)$.

Çalışmamız farklı evrelerde ve nispeten çok sayıda hasta içeren bir çalışma olmasına rağmen esas olarak retrospektif olmasından kaynaklanan bazı önemli kısıtlamaları vardır. Bu çalışma tek merkezli bir çalışmadır. Hastaların bir kısmında, biyopsi alınmadığı çin, histolojik değerlendirme yapılamamıştır. H. pylori enfeksiyonu sadece bir yöntemle teşhis edilmiştir. Sunulan sonuçlar dışında, hastaları anormal endoskopi veya histolojiye duyarlı hale getirebilecek ilaç kullanımı, komorbiditeler gibi diğer potansiyel risk faktörleri tam olarak belirlenememiştir.

Sonuç olarak hem diyalize giren hem de diyalize girmeyen $\mathrm{KBH}$ hastalarının büyük çoğunluğunda endoskopik olarak üst GiS patolojisi tespit ettik ve bu hastaların histolojik değerlendirmesinde gastrik premalign lezyon olan iM görülme oranı oldukça yüksekti. Bu nedenle özellikle böbrek nakli planlanan hastalarda üst GiS endoskopik ve histolojik değerlendirme bu hastalar için kabul edilebilir bir prosedürdür.

\section{"Tüm yazarlar herhangi bir çıkar çatışması olmadığı- nı beyan ederler."}

\section{KAYNAKLAR}

1. Shirazian S, Radhakrishnan J. Gastrointestinal disorders and renal failure: exploring the connection. Nat Rev Nephrol 2010;6:480-92.

2. Kızıltaş $S$, Sahin S. Upper gastrointestinal disorders among dialysis patients. ACU Sağlık Bil Derg 2019;10:135-41.

3. Misra V, Misra S, Shukla S, et al. Endoscopic and histological changes in upper gastrointestinal tract of patients with chronic renal failure. Indian J Pathol Microbiol 2004;47:170-3.

4. Khedmat H, Ahmadzad-Asl M, Amini M, et al. Gastro-duodenal lesions and Helicobacter pylori infection in uremic patients and renal transplant recipients. Transplant Proc 2007;39:1003-7.

5. Nardone G, Rocco A, Fiorillo M, et al. Gastroduodenal lesions and Helicobacter pylori infection in dyspeptic patients with and without chronic renal failure. Helicobacter 2005; 10:53-8. 
6. Stolic RV, Jovanovic AN, Peric VM, et al. Influence of the level of renal insufficiency on endoscopic changes in the upper gastrointestinal tract. Am J Med Sci.2008;336:39-43.

7. Kang JY, Ho KY, Yeoh KG, et al. Peptic ulcer and gastritis in uraemia, with particular reference to the effect of Helicobacter pylori infection. J Gastroenterol Hepatol 1999;14:771-8.

8. Karari E, Lule G, McLigeyo S, Amayo E. Endoscopic findings and the prevalence of Helicobacter pylori in chronic renal failure patients with dyspepsia. East Afr Med J 2000;77:406-9.

9. Niknam R, Barfei M, Mahmoudi L. Helicobacter pylori, endoscopic, and histologic features among kidney transplant candidates in Southern Iran. Infect Drug Resist 2019;12:3687-93.

10. Homse Netto JP, Pinheiro JPS, Ferrari ML, et al. Upper gastrointestinal alterations in kidney transplant candidates. J Bras Nefrol 2018;40:266-72.

11. Bacci M, Russo F, Carvalho G, et al. Endoscopic alterations in a cohort of hemodialysis patients: a cross-sectional study. Int J Gen Med 2014;7:459-61.

12. Wesdorp RI, Falcao HA, Banks PB, Martino J, Fischer JE. Gastrin and gastric acid secretion in renal failure. Am J Surg 1981;141:334-8.

13. Ravelli AM. Gastrointestinal function in chronic renal failure. Pediatr Nephrol 1995;9:756-62.

14. Gawron AJ, Shah SC, Altayar O, et al. AGA technical review on gastric intestinal metaplasia natural history and clinical outcomes. Gastroenterology 2020;158:705-31.
15. Altayar O, Davitkov P, Shah SC, et al. AGA technical review on gastric intestinal metaplasia epidemiology and risk factors. Gastroenterology 2020;158:732-44.

16. Huang C, Chen Q, Jiang J, et al. Gastric metaplasia and Helicobacter pylori infection in hemodialysis patients. Ren Fail 2012;34:420-4.

17. Li KJ, Chen L. Association between duration of dialysis and Helicobacter pylori infection in dialysis patients: a meta-analysis. Int Urol Nephrol 2019;51:1361-70.

18. Shin SP, Bang CS, Lee JJ, Baik GH. Helicobacter pylori infection in patients with chronic kidney disease: A systematic review and meta-analysis. Gut Liver 2019;13:628-41.

19. Chang SS, Hu HY. Lower Helicobacter pylori infection rate in chronic kidney disease and end-stage renal disease patients with peptic ulcer disease. J Chin Med Assoc 2014;77:354-9.

20. Erkut M, Uzun DY, Kaklıkkaya N, Fidan S, et al. Sociodemographic characteristics and clinical risk factors of Helicobacter pylori infection and antibiotic resistance in the Eastern Black Sea region of Turkey. Turk J Gastroenterol 2020;31:221-33.

21. Jaspersen D, Fassbinder W, Heinkele $P$, et al. Significantly lower prevalence of Helicobacter pylori in uremic patients than in patients with normal renal function. J Gastroenterol 1995;30:585-8. 